\title{
FUNDAÇÃO DA SBQ OU O QUE OS JOVENS PRECISAM SABER
}

\author{
Claudio Airoldi \\ Instituto de Química, Universidade Estadual de Campinas, CP 6154, 13084-971 Campinas - SP, Brasil
}

Recebido em 29/6/07; aceito em 14/3/08; publicado na web em 26/9/08

\begin{abstract}
FOUNDATION OF SBQ OR WHAT THE YOUNG PEOPLE MUST KNOW. This report has an objective to contribute the understanding of some historical features associated with the preceding period before SBQ foundation on $8^{\text {th }}$ July of 1977 . There are some descriptions involving chemist meetings to decide the strategy of splitting from the Brazilian Society for the Progress of Science (SBPC), in order to be independent on annual meeting organizations. The military political situation forced the annual SBPC meeting transference from Fortaleza to São Paulo, where the chemist assembly took place in PUC and the SBQ was definitively founded. The actual powerful of the Society and its successful in completing the thirty years anniversary is also exalted.
\end{abstract}

Keywords: SBQ; foundation; meeting.

\section{INTRODUÇÃO}

A nossa bem sucedida Sociedade Brasileira de Química (SBQ) tornou-se adulta, ao completar os 30 anos de idade, e se impõe com muita personalidade dentro do cenário da comunidade científica nacional e internacional. Como poderiam dizer os químicos que atuam há mais tempo nesse ramo da ciência, imitando o velho jargão popular - parece que a acanhada Sociedade foi fundada ontem e veja lá quanto tempo já se passou. Realmente o tempo se pôs a caminho em desenfreada corrida e tantos fatos importantes aconteceram, com participação efetiva da SBQ, nessas três décadas. Como se trata de uma Sociedade com vínculos muito estreitos com a vida acadêmica, o seu crescimento esteve intimamente ligado à Universidade. Sem se prender a dados quantitativos, durante esse período, as Universidades existentes cresceram, outras novas foram criadas, e todas vêm-se expandindo com formação contínua de graduandos em Química e especialidades afins, fortalecendo assim a Sociedade que congrega tais profissionais.

Para que o jovem dos dias de hoje possa se inteirar do panorama relacionado à Química dos já passados 30 anos, as escolas públicas formadoras de profissionais, que pudessem efetivamente exercer atividades em ensino, eram restritas. Isto porque os cursos de pósgraduação estavam em estágios iniciais de implantação, sem que houvesse uma massa crítica para suportar as exigências da época, tanto assim que muitos acadêmicos da época adquiriram tal capacitação em grandes Universidades estrangeiras. O argumento vigente e correto sobre a ausência de escolas formadoras de químicos é que realmente o curso era dispendioso, além de poucos os eventuais profissionais que poderiam potencialmente exercer as funções tanto em pesquisa, como no ensino. Para sanar esse aparente empecilho, estrangeiros de várias áreas foram convidados para suprir aqui essa demanda vigente, espelhando as idéias no bom exemplo de procedimento anterior, de enorme sucesso, por ocasião da fundação da Universidade de São Paulo (USP). ${ }^{1}$ Em ambas as participações distintas muitos deles se radicaram no país, exerceram as atividades a que se propuseram, formaram discípulos propagadores desses mesmos ideais e se destacaram profundamente no campo profissional.

Dentro desse mesmo retrospecto, deve-se lembrar que naquela época não existia, como hoje, uma proliferação de escolas superiores da rede particular, atuando em vários segmentos universitários. Desta

\footnotetext{
*e-mail: airoldi@iqm.unicamp.br
}

forma, o número de vagas era minguado, insuficiente para satisfazer a demanda, mesmo considerando a população existente na época, o que levava a uma competição acirrada entre os vestibulandos para galgar uma posição desejada na Universidade. Com o passar do tempo, à lista dos aprovados foi acrescentado um número adicional que, eventualmente, poderia ser chamado em função da desistência de alguns dos relacionados e esta passou a ser chamada de lista dos excedentes. Este fato por certo foi também um dos motivos adicionais que pressionaram as Universidades para que houvesse abertura de novas vagas em etapas posteriores.

Vale ressaltar que, em se tratando da Química em si, no começo da década de 60, no estado de São Paulo, existiam apenas dois centros, o já bem estabelecido na USP ${ }^{1}$ com início em 1935 e a recém formada escola de Araraquara, atual Universidade Estadual Paulista (UNESP), ${ }^{2}$ tendo o primeiro vestibular realizado em 1961. Na década seguinte, houve uma considerável expansão das Universidades, também porque se iniciavam em várias delas os cursos de pós-graduação, tendo uma participação até mais efetiva dos estrangeiros contratados.

Como seria justo de esperar, com o passar do tempo, o desenvolvimento da ciência na direção das novas fronteiras do conhecimento humano naturalmente influenciou a Química, que expandiu também no acompanhamento do saber na busca de novos rumos. Particularmente no nosso país, o crescimento foi favorecido pelos intercâmbios constantes com centros de pesquisas internacionais, além da implantação constante de uma variedade de cursos de pós-graduação, com reflexo tanto no sistema de ensino, acompanhado por significativo financiamento da pesquisa. ${ }^{3}$ Como resultado, houve uma resposta da comunidade, com inserção de grande número de jovens entusiastas, com interesses variados, sempre em completa sintonia com os relevantes aspectos da literatura especializada, o que provocou uma expansão de maneira exponencial, num incremento de produtividade e favoráveis perspectivas futuras, ${ }^{4}$ que coloca a Química atual em posição de reconhecimento no cenário internacional. ${ }^{5}$

O que se enfoca nessa descrição é o despertar nos jovens cientistas brasileiros curiosidades adicionais, voltadas para a etapa já distante pouco conhecida, anterior até aos 30 anos e talvez a indagação mais corriqueira fosse, como que a Química se inseria no contexto nacional em termos de projeção como sociedade? Claro que sempre existiram os líderes nos vários campos, que brilhantemente se destacavam pela produtividade, principalmente nas escolas mais tradicionais, que sobressaiam com melhores condições para o desenvolvimento de 
pesquisa e, conseqüentemente, chamavam a atenção da comunidade da época. Porém, como era de se esperar, a representatividade dos químicos nos órgãos públicos era feita através das indicações através dos conselhos regionais de químicos ou da já existente Academia Brasileira de Ciências, para que exercessem as funções específicas. Enfim, sempre se ajustava uma maneira para que a consulta chegasse a bom termo e, como acontece ainda hoje, havia os que se descontentassem das indicações representativas junto ao governo, como por exemplo, nas participações em órgãos de fomento à pesquisa. Esse procedimento, porém, difere bruscamente da sistemática atual, que apresenta transparências nas representatividades requeridas.

\section{DIVULGAÇÃO DOS RESULTADOS}

Em termos de mostra de idéias através de congressos, para que fossem expostos os resultados das pesquisas em andamento, assim como a Química, as outras ciências denominadas exatas estavam diretamente ligadas à Sociedade Brasileira para o Progresso da Ciência (SBPC). Essa ampla Sociedade congregava todos os segmentos relacionados às ciências humanas e exatas, desempenhava um papel importante principalmente em relação às manifestações políticas e teve aspecto relevante como foro de exposição de idéias, facilitando as discussões a respeito das diretrizes educacionais críticas em relação à própria distribuição de verbas dos órgãos governamentais.

Essa Sociedade teve participação relevante no período conturbado do regime do governo militar, navegou em águas turbulentas, em atmosfera pesada nos chamados anos de chumbo, ${ }^{6-8}$ cujo governo ditatorial tentava de todas as maneiras silenciar a sociedade brasileira e deixar mudas as florescentes manifestações que surgiam em prol da liberdade de expressão, num mundo repleto de idéias novas que se agitava e iria marcar em destaque os denominados acontecimentos dos anos 60 e 70. No afã de sobrepujar a imposição marcante da época, a SBPC cresceu de maneira assustadora por ser praticamente o único canal de manifestação plausível. As reuniões anuais aconteciam em clima de grande expectativa e parte dos químicos sentia que já havia uma massa crítica mesmo incipiente para se pensar na formação de uma sociedade independente, com diretrizes próprias, na organização de encontros regionais ou mais abrangentes, que poderiam envolver toda a comunidade. As conjeturas a respeito caíam em divagações constantes, que de fato se concretizasse, automaticamente implicaria na ruptura com a já estabelecida infra-estrutura organizacional dos eventos anuais, amplamente suportada pela sociedade atuante, além da possível divisão de forças e conseqüente enfraquecimento no combate ao indesejável status quo.

Os princípios de formação de uma Sociedade foram aos poucos amadurecendo com o passar do tempo e sempre por ocasião da reunião anual havia encontro de químicos, de maneira bastante informal, em corredores dos eventos ou em salas previamente reservadas para tal finalidade, com manifestações desejosas dos vários segmentos de interessados, com discussões sobre as possíveis propostas, que muito embora fossem difusas, e como muitos projetavam essas intenções que um dia deveriam ser levadas adiante de maneira definitiva. Claro que depois de alguns ensaios, esse fato foi concretizado numa reunião marcada para se levantar o problema na Universidade de Brasília, quando então se realizaria a reunião anual da SBPC, em plena vigência do regime ditatorial, em meados de 1976. Alguns dos químicos interessados lá compareceram, num anfiteatro daquela Universidade, para examinar e discutir a possível proposta. Ao ser apresentada apareceram mais argumentos contra do que a favor, tendo como ponto principal o fato de que a futura sociedade não teria condições de organizar um encontro, enquanto que naquela atual conjuntura toda infra-estrutura era prontamente fornecida pela SBPC, pois, tinha mais representatividade, que mesmo em condições adversas ao governo militar, conseguia com competência organizar anualmente reuniões em locais previamente estabelecidos, em distintas cidades brasileiras.

Diante do impasse criado, tudo parecia estar direcionado para a manutenção do status quo, com certo pessimismo em até levar adiante as intenções prévias. Foi nesse clima pouco encorajador que o articulista, juntamente com outro colega (Carlos A. Filgueiras), resolveram tomar as rédeas na defesa da proposta e insistiram, de maneira enfática, na tentativa de convencer os presentes que aquele era o momento adequado para a tomada de posição e que deveria ser criada a sociedade sim. Porém, no sentido de evitar uma decisão prematura, a proposta foi aprovada pela assembléia por pequena margem de votos, com uma ressalva de que a decisão mais racional, com maior participação dos representantes da Química, deveria ser tomada na próxima reunião anual, após se ter o respaldo dos profissionais atuantes no campo através de uma consulta ampla. Enfim, toda a comunidade deveria tomar conhecimento através de questionários devidamente preparados para essa finalidade. Houve um pronto atendimento dos presentes, mesmo dos que pouco acreditavam em sucesso, com várias manifestações, em levar não só ao local de trabalho, mas também a outros profissionais atuantes em outros centros de pesquisas, onde houvesse participação de químicos. Essa seria a expectativa que aguardaria a comunidade e todos se empenhariam em levar a proposta naquele período de um ano.

\section{PRÓXIMA REUNIÃO}

No final da reunião anual da SBPC, como sempre acontecia, a assembléia geral acatou o convite estabelecido pelos associados do Ceará e o próximo encontro deveria ser em Fortaleza. Porém, naquele ano e no seguinte, a ditadura fechava o cerco de maneira abusiva com claro cerceamento das liberdades de reuniões, ${ }^{6-8}$ e para a SBPC também não haveria exceção, muito embora todos soubéssemos que se a mesma acontecesse seria altamente vigiada. Pouco tempo antes da marcada reunião de Fortaleza, quando tudo já se encaminhara para tal, o governo militar tomava decisão e divulgava uma nota por todos os meios de comunicação que, por motivo de precaução, a mesma seria evitada para minimizar o encontro de muitas pessoas, que poderiam causar distúrbios sociais, principalmente por problemas de divulgações de preceitos comunistas, com conseqüentes perturbações de ordem pública.

Em decorrência dos acontecimentos e como se estivesse inserido no clima reinante, esta nota caiu como uma verdadeira bomba em todas as Universidades, com claras manifestações individuais e coletivas em defesa e fortalecimento da SBPC, através da filiação de novos sócios, no que houve uma resposta muito positiva, forçando assim o aumento de sócios num atendimento maior à reunião naquele ano. Ao mesmo tempo, os segmentos liberais que ainda tinham acesso ao governo ditatorial buscaram uma solução passiva, com o intuito de tornar viável o encontro proposto. Como resultado de entendimentos de vários segmentos da sociedade, a reunião foi remarcada então para a Pontifícia Universidade Católica (PUC) de São Paulo, por oferta do recinto através do cardeal D. Paulo Evaristo Arns, a quem aquela Universidade estava subordinada, mesmo se sabendo que o cardeal era um sustentáculo na oposição ao regime vigente. A propósito dessa mudança de local se encontra relatado na apresentação dos Simpósios da Sociedade, fato que se deu mais tarde, quando o apresentador se manifestou "editarão os volumes correspondentes à XXIX Reunião Anual, programada para Fortaleza e realizada afinal em São Paulo, por motivos já muito conhecidos". ${ }^{9}$ De qualquer maneira, essa abertura dada à Sociedade era uma benevolência do momento porque conseguiam os dirigentes governamentais ter a reunião próxima aos órgãos repressores melhores equipados, o que levaria a maior efici- 
ência no possível controle do evento. De fato, a reunião transcorreu sem incidentes maiores que chamassem a atenção, pelo menos para o grande público.

Foi nesse clima de insatisfação política que a reunião dos químicos teve lugar em uma sala devidamente reservada para que se tomasse a decisão no dia 8 de julho de 1977. Estavam presentes cerca de 80 interessados, como representantes da maioria dos estados brasileiros, reunidos na sala 056 da PUC, e pelo que se podia sentir é que a fundação de uma Sociedade estava pelo menos aceita pela comunidade, pois, $69 \%$ dos 419 entrevistados responderam afirmativamente, ${ }^{10}$ fato que foi bastante tranqüilo porque os possíveis representantes já tinham absorvidos as necessidades inerentes da proposta do ano anterior.

\section{A FUNDAÇÃO}

Uma preocupação cabível de discussão era como seria feito o estatuto da Sociedade, quem poderia pertencer à mesma, como organizar a eleição, qual mandato, quantos membros deveria ter a diretoria, que tipo de revista científica deveria publicar, que tipos de artigos, a revista concorreria com as demais existentes, qual o nome etc. Muitos externaram suas opiniões, em breves discussões, tendo a frente todo o entusiasmo contagiante daquele que se tornaria o Primeiro Secretário da Sociedade. Enfim, para se ter um documento que comprovasse aquela fundação da nascente Sociedade Brasileira de Química, foi passada uma simples folha de papel almaço para que os presentes firmassem os nomes. Neste ponto, um colega (Osvaldo A. Serra) teve idéia em apresentar uma pequena cartolina, que era o símbolo de protesto da reunião anual, tendo estampada a figura do eminente cientista Galileo Galilei. Propôs que todos assinassem, o que de imediato foi bem acolhido e esta seria a capa do primeiro fascículo da também sugerida e nascente revista ${ }^{7}$ que trouxesse algo diferente, inovador, daí Química Nova, segundo a proposição (Eduardo M. A. Peixoto). Concretizavase ali sobre a efígie de Galileo o caráter simbólico da plena rebeldia da coletividade científica dos anos 70 contra a ditadura militar, pois, igualmente o eminente cientista italiano se opusera frontalmente contra a inefável atuação da afamada Inquisição, em séculos de terror e perseguições aos contrários aos dogmas estabelecidos pela Igreja.

Como sempre acontece em reuniões em que congregam profissionais afins, algumas curiosidades merecem destaque e vale a pena aqui relatar dois fatos. O que chamou atenção é que dentre todos os presentes, apenas um se recusou a assinar sobre a efígie de Galilei. Tomou a palavra e enfaticamente argumentou em discurso inflamado que esse cientista havia sido um herege em relação à Igreja católica e não merecia tal consideração, concluindo que jamais poderia trair os seus princípios religiosos e, portanto, não merecia ser lembrado em quaisquer circunstâncias. No segundo caso, foi a argumentação defendida por raciocínios tortuosos por um dos participantes, no sentido de que a proposta de formação de diretoria deveria apenas conter os físico-químicos, pois, somente eles eram os sustentáculos das contribuições relevantes de pesquisadores no país e seriam os mais aquinhoados no cenário científico brasileiro merecendo, assim, a composição majoritária na nova diretoria. Após a citação de alguns nomes, houve um sério constrangimento no recinto, até com poucos argumentos contrários, talvez pelo respeito ao proponente e também por ser na época um regime de liberdade vigiada, e os possíveis confrontos deveriam ser amenizados, evitando-se discordâncias que, eventualmente, pudessem se tornar inoportunas na ocasião. A Assembléia findou com a escolha de nomes que foram inicialmente apontados e aprovados através de manifestação dos presentes, sendo assim constituída a primeira diretoria da nova Sociedade. Detalhes adicionais encontram-se na manifestação do Editorial do primeiro fascículo da revista ${ }^{9}$ e é claro que a secretaria estava ao encargo do Prof. Peixoto, que teve atuação importante nas diretrizes dessa nova sociedade.

Como todos já sabem, daí para frente os registros comprovam bem toda a formação da SBQ e para que se tenha um pequeno histórico dos primórdios não registrados até o momento, se conclui esse relato igualmente como o fez Gonçalves Dias na extraordinária obra, através da manifestação do famoso guerreiro indígena I-Juca Pirama: "meninos eu vi". ${ }^{11}$

\section{REFERÊNCIAS}

1. Senise, P.; Origem do Instituto de Química da USP - Reminiscência e Comentários; Instituto de Química: São Paulo, 2006.

2. Luiz, N. M.; Histórico: UNESP, Instituto de Química, Campus de Araraquara, documento não publicado, 1991

3. de Andrade, J. B.; Cadore, S.; Vieira, P. C.; Zucco C.; Pinto, A. C.; Quim. Nova 2003, 26, 445.

4. de Andrade, J. B.; Pinto, A. C.; Cadore, S.; Vieira, P. C.; Zucco C.; Pardini, V.L.; Curi, L.R.L.; Quim. Nova 2005, 28, S7.

5. Mangrich, A.S.; Quim. Nova 2006, 29, 893.

6. Gaspari, E.; A ditadura Derrotada; Companhia das Letras: São Paulo, 2003.

7. Gaspari, E.; A ditadura Escancarada; Companhia das Letras: São Paulo, 2002.

8. Gaspari, E.; A ditadura Evergonhada; Companhia das Letras: São Paulo, 2002.

9. Reis, J.; Simpósios da $28^{a}$ Reunião Anual da Sociedade Brasileira para o Progresso da Ciência, julho de 1976, Brasília, Cerifa Gráfica e Editora Ltda: São Paulo, p. v, 1978.

10. Peixoto, E. M. A.; Quim. Nova 1978, 1, 26.

11. Gonçalves Dias, A.; Antologia Poética, $5^{\mathrm{a}}$ ed.. Agir: Rio de Janeiro, 1969. 